Article

\title{
Why Does Context Really Matter? Understanding Companies' Dialogue with Fringe Communities
}

\author{
Pablo Rodrigo ${ }^{1}$ (D) and Ignacio J. Duran ${ }^{2, *(D)}$ \\ 1 Strategy Department, Escuela de Negocios, Universidad Adolfo Ibáñez, Viña del Mar 2562340, Chile; \\ prodrigo@uai.cl \\ 2 Institute for Social Innovation, Universitat Ramon Llull-ESADE Business School, 08172 Barcelona, Spain \\ * Correspondence: ignacio.duran@esade.edu
}

check for

updates

Citation: Rodrigo, P.; Duran, I.J. Why Does Context Really Matter?

Understanding Companies' Dialogue with Fringe Communities.

Sustainability 2021, 13, 999.

https://doi.org/10.3390/su13020999

Received: 8 December 2020

Accepted: 14 January 2021

Published: 19 January 2021

Publisher's Note: MDPI stays neutral with regard to jurisdictional claims in published maps and institutional affiliations.

Copyright: (C) 2021 by the authors. Licensee MDPI, Basel, Switzerland. This article is an open access article distributed under the terms and conditions of the Creative Commons Attribution (CC BY) license (https:/ / creativecommons.org/licenses/by/ $4.0 /)$.

\begin{abstract}
Although scholars have studied stakeholder dialogue, we lack studies that understand the effect of context on the structure and form of dialogue. To address this gap, in this research we focus on local rural communities that can be classified as fringe stakeholders to develop a comprehensive model of "fringe community dialogue". As these neglected groups have been marginalized from society and face grave serious socio-environmental issues, we argue that these characteristics will affect the way dialogue occurs. Therefore, we posit that these instances need to be tailored to this specific stakeholder. To assess this, we follow a theory-building grounded theory approach, and as field of research we extract information from three different research sites. Findings indicate that, because of the characteristics of fringe communities, dialogues must follow three sequential dimensions, which are connected by two enabling mechanisms. We contribute by evincing that, because of this stakeholder's characteristics, the dialogue process has a particular structure and key variables, differing from what the past literature asserts.
\end{abstract}

Keywords: communities; fringe stakeholders; grounded theory; stakeholder dialogue; stakeholder theory

\section{Introduction}

The literature on stakeholder dialogue has been prolific in unveiling the needed conditions for organizations to communicate with constituent parties, e.g., [1,2]. Dialoguing implies that companies meet and interact with stakeholders [3,4], and although several aims may be sought $[5,6]$ the main goal usually is to expose stakeholders' concerns to assess and decide actions that address these issues [7,8]. The expected outcome is gaining stakeholders' support by improving the entities' socio-environmental performance [9].

Despite the contributions made, extant theory on stakeholder dialogue fails to take a contextual approach. This means that insights are "generic" [10,11]: current research conceives dialogue without considering the characteristics of the place or people involved. Reviews show that general guidelines for talks exist, without mentioning how these matters are contingent on the milieu analyzed, e.g., [12,13]. Therefore, we ignore the underpinnings of talking with groups in different social settings, such as those stakeholders that are marginalized and face harsh socio-environmental conditions. This is relevant because depending on the context dialogues could be different and more complex that what mainstream research indicates. Ferri et al. [3], for example, suggest that companystakeholder relationships vary depending on the institutional context, and in certain settings they could be tougher to develop.

We posit that dialogues should be tailored to respond to the contextual features of the stakeholder involved in the dialogues. To study this, we focus on local, rural communities that fit the description of fringe stakeholders. Fringe stakeholders are poor, uneducated, powerless, and isolated groups that are affected by companies [14,15]. As oftentimes productive sites are located far from large cities, the people enduring firms' impacts are 
nearby marginalized settlements [16,17]. We therefore argue that dialogue attributes should respond to the factors that characterize this particular stakeholder, and not necessarily to those suggested in mainstream literature.

To comprehend this issue, this article addresses the following research question: How do companies dialogue with fringe communities? We answer by following a grounded theory approach $[18,19]$ because it is well-suited to inductively develop frameworks by discovering emergent constructs and linkages between them, especially when we know little about the phenomenon [20]. Our in-depth study is based on three sites, where we probe into the corresponding company-fringe community dialogue. As an empirical field of inquiry, we chose extractive sectors as they not only tend to operate in remote areas surrounded by powerless and impoverished communities, but also interact with these stakeholders due to firms' socio-environmental impacts [21,22].

This article contributes to the field in two ways. First, we contribute by showing that dialogues are not generic endeavors. We therefore challenge extant theory by showing that fringe community dialogue entails a particular process with some steps and variables that have not appeared in past research. For example, we hint that companies initially must give resources to fringe communities that normally governments would provide. Second, we unpack the structure of fringe community dialogue by deriving a sequential model that better reflects the subtleties of this process. The novel discovery here is that we find that there is a particular ordered way to unfold the dialogue process. In this sense, in contrast to what extant theory proposes, this process encompasses three interrelated stages: "Dialogue Groundwork", "Dialogue Conformation", and "Dialogue Reinforcement". Each one has its own purpose and sub-variables that further explain this endeavor. In this sense, we answer our research question, and we add to the ongoing discussion on how to dialogue with fringe communities, e.g., [23,24].

\section{Theoretical Background}

\subsection{The Lack of Contextual Research in Stakeholder Dialogue}

Scholars research stakeholder dialogue to determine how to converse with constituent groups $[6,12,13]$. It is conceived as an interactive process between organizations and stakeholders where a communication channel is built to develop a better form of understanding [3]. Dialogue is implemented as instances (e.g., meetings) where the parties involved swap information, interact, and discuss matters to subsequently find solutions to existing concerns $[25,26]$. From a practitioner point of view, it has become a tactic to deal with stakeholders that affect or are affected by firms [27,28]. Although stakeholder dialogue may have several goals [5], the most pervasive are building trust [7,8], a meaningful relationship [9,29], obtaining legitimacy [10,30], and/or reduce risk [31,32].

This tradition has developed stakeholder dialogue typologies, e.g., [2,4] and determined necessary features for effective conversations with constituent groups. Although a revision of these studies is beyond the scope of this article, most approaches agree on certain attributes. For example, that dialogue implies moving away from monologic towards two-way communication, where all parties manifest their position and learn from the experience $[7,13]$. Openness and transparency are also major themes, where company and stakeholder are honest regarding their goals and expectations of the dialogues $[5,33,34]$. Talks also are an opportunity to better comprehend existing socio-environmental problems between organizations and stakeholders [12,35], to then propose solutions that guide companies' decision making $[1,36]$. Additionally, there is a notion of structure: dialogues have milestones or steps that must be followed (e.g., adequate number of meetings) [27,37].

Despite these findings, what we lack is a "contextual" approach to stakeholder dialogue. Thus far, dialogue is construed as something you "do" generically: that is, without considering contextual elements [11], as extant theory has not investigated how conversations are molded to match a particular population [25]. Echoing this, Aakhus and Bzdak [10] coin the concept of "communication design practice", which suggests that talks should "fit" the reality the organization faces. That is, dialogues should, for example, be designed to 
respond to the specific characteristics and expectations of the stakeholder involved. Otherwise, the process will likely fail: entities would not reap positive outcomes and instead run into intricate scenarios such as rising costs and participant attrition/hostility [7,28,32,37].

Therefore, until now, we have ignored how key stakeholder dialogue variables, such as two-way communication, openness, transparency, comprehension, decision making, and structure, differ depending on where a company operates, or the type of stakeholders involved. Moreover, we do not know if these features are essential in every version of dialogue. These gaps are unfortunate, as works have called for more contextual approaches to stakeholder dialogue to unpack the nuances of meeting with parties in dissimilar settings, e.g., $[3,6]$.

\subsection{Fringe Stakeholder Dialogue: Focusing on Local Communities}

Following Hart and Sharma [14], fringe stakeholders are those groups that endure severe socio-environmental conditions and are marginalized, poor, and powerless. Few works attempt to understand how companies deal with these parties, e.g., [38-40], and these studies delve into matters such as cross-sector collaboration or stakeholder perceptions. Yet, they do not tackle stakeholder dialogue. What they do reveal, however, is that fringe stakeholders have unique characteristics that could make conversations more complex. McCarthy and Muthuri [15], for example, realize that because these groups have less voice, power, and urgency, instances that require participation (e.g., dialogue) must guarantee inclusiveness, so everybody talks. Daudigeos et al. [23] concurs with this, positing the need for an inclusive corporate-stakeholder relationship. Both articles agree that given the inherent experiences of fringe stakeholders (e.g., exclusion), communication needs to be different from what mainstream literature indicates, emphasizing the need to customize dialogues (like Aakhus and Bzdak's [10] suggestion). Otherwise, due to these differences, companies will not comprehend their grievances nor will they design appropriate responses.

To comprehend how dialogue with these groups unfolds the focus should be put on local communities, which oftentimes fit the description of fringe stakeholders. We allude to what Dunham et al. [41] coin "community of place" or Calvano [42] "fence-line community". That is, groups that are close to the firm's location and have face-to-face interaction with organizational representatives. Although "local community" may be difficult to define [43], most community-specific works share this understanding of the construct, e.g., [17,22,44-49].

Hence, a local community that can be classified as fringe stakeholder (fringe communities, hereafter) are meager, isolated, and disadvantaged settlements near companies, which also face complex social-environmental issues. The existence of these communities is pervasive, as they can be found in developed countries such as Australia [45], Canada [46], New Zealand [39], Sweden [50], and United States [16]. Yet, they generally are more common in emerging markets, particularly Latin America [21,24,44], Africa [51,52], and Asia [40]. It is therefore not unusual for enterprises worldwide to operate close to fringe communities, especially when companies function close to extractive resources and/or small villages.

The problem is that knowledge on fringe community dialogue is not only scant [1], but also fragmented. The few existing works have not unpacked this phenomenon because they focus on discrete aspects, failing to explain its inner complexity and distinct attributes (i.e., the underlying characteristics of its process). For instance, Anguelovski [44] endorses having iterative dialogues with fringe communities to solve conflicts, while Dare et al. [45] show that certifications could enrich this process by raising managerial awareness. Holley and Mitcham [16] and $\mathrm{Ni}$ et al. [48] reveal that two-way communication reduces uncertainty during meetings, Keenan et al. [53] suggests a gender approach in fringe community dialogue because women may be more affected than men, and Lehtimaki and Kujala [54] focus on how language affects the development of the conversation. Therefore, we still have not grasped fringe-stakeholder dialogue in a comprehensive manner.

The fact that extant theory neglects delving into dialogue with fringe communities poses a social issue. This disregard is fertile ground for companies' human rights viola- 
tions [29]. Unlike "regular" communities, marginalized groups do not have the means to easily "remind" companies of their duty to respect basic rights $[4,7]$, such as a safe working environment or a clean ecosystem. Hence, even inadvertently, when companies prioritize other stakeholders, they could forget to fulfill rudimentary necessities or respect their fringe communities. Parsons [49], for instance, shows that enterprises do not always honor their identity. McDonald et al. [47] evidence that firms may exploit fringe community members' unpaid labor. Babidge [21] exemplifies how a mining corporation limited a town's access to water, and Roper et al. [39] report how local communities may be forgotten in forestryfarming projects that directly involve them, bypassing their right to a voice. However, as some posit, e.g., [28], a way to solve these problems and integrate marginalized groups in firms' decision making and uphold their dignity is through dialogue.

Thus, following recent calls, e.g., $[17,23,53]$, there seems to be a growing need to learn how to dialogue with fringe communities to avoid violating basic rights. Our study responds to this precise concern, as we seek to understand the nuances of how this process occurs.

\section{Methodology}

\subsection{Research Setting}

In grounded theory site selection follows the principle of theoretical sampling, where sites are not chosen arbitrarily nor to enhance statistical generalizability, but due to conceptual relevance $[18,19]$. Therefore, the settings were chosen based on their appropriateness to answer our research question, and hence unveil how dialogues between companies and fringe communities occur. For this reason, the selected sites simultaneously fulfilled three conditions: (1) the existence of a settlement that fits the description of a fringe local community (i.e., marginalized, poor, and listless); (2) the presence of a significant industrial facility that has a socio-environmental impact on those people; and (3) dialogue instances between these two parties have taken place.

Following these criteria, as a field of study we chose Chilean extractive industries for two reasons. First, the economy of this nation is strongly dependent on these sectors [55], so these companies impact thousands of citizens and firms oftentimes address the concerns of these people, for example, through dialogue. In fact, evidence suggests that Chilean managers have increasingly recognized the value of stakeholder engagement [56], and this is especially true in this country's extractives industries, where these companies already engage their stakeholders [57]. Second, extractive firms in Chile are usually located far from urban centers, where natural resources are available for extraction, and thus deal with the harmed, remote, and poor (fringe) communities that surround these areas, e.g., [21]. Therefore, the Chilean context is well-suited to fulfill the aim of this investigation, as we can find extractive organizations that dialogue with fringe communities.

Three different sites were selected, each consisting of a company-fringe community dyad. The setting heterogeneity is explained because following the principle of theoretical sampling [19], we sought to capture a broad range of realities concerning dialogues between these parties to obtain as much conceptual insight as possible. Therefore, although these communities can be considered as fringe, they represent diverse backgrounds in demographic, geographic, wealth, and social terms. In all locations we gathered qualitative data to understand how dialogues were maintained between companies and fringe communities. We refer to them as research sites A, B, and C, respectively. (Due to confidentially agreements, we cannot provide information that may help identify the firms involved. Therefore, we describe them succinctly. However, because our focus is to inductively develop new insights concerning the dialogue process itself, revealing which are the actual entities is not strictly necessary see, [19].) Location A involved an international, mediumsized forestry firm located in central Chile; site B concerned a large mining firm in northern Chile; and site $C$ considered a multinational, yet small aquaculture firm in southern Chile. In site $\mathrm{A}$, the fringe community was a medium-sized rural town that is highly dependent on the company's job opportunities, but also endures its environmental externalities; in 
site B it is a very small rural settlement environmentally affected by the mining activities of the company; and site $C$ it is a small rural town socio-environmentally impacted by the aquaculture firm.

Table 1 presents a detailed description of the three settings, including their approximate location and a brief account of each firm and fringe community.

Table 1. Research sites information.

\begin{tabular}{|c|c|c|c|}
\hline & Research Site A & Research Site B & Research Site C \\
\hline Approximate location & $\begin{array}{l}\text { A lumber facility located about } \\
550 \mathrm{~km} \text { South of Santiago. }\end{array}$ & $\begin{array}{c}\text { A mine located about } 1500 \mathrm{~km} \\
\text { North of Santiago. }\end{array}$ & $\begin{array}{l}\text { A fishing site located about } \\
1200 \mathrm{~km} \text { South of Santiago. }\end{array}$ \\
\hline Company description & $\begin{array}{c}\text { Medium-sized forestry firm } \\
\text { (about 14,000 employees). } \\
\text { Horizontally and vertically } \\
\text { integrated, produces a wide range } \\
\text { of forestry products in three } \\
\text { different nations, and sells } \\
\text { worldwide. } \\
\text { Owns several assets: such as } \\
\text { forests, factories, and commercial } \\
\text { offices. }\end{array}$ & $\begin{array}{l}\text { Large mining corporation } \\
\text { (more than } 25,000 \text { employees). } \\
\text { Extracts, refines, and sells } \\
\text { different minerals, and } \\
\text { chemical sub-products locally } \\
\text { and internationally. } \\
\text { Has operations in several } \\
\text { parts of Chile. }\end{array}$ & $\begin{array}{l}\text { Small aquaculture firm } \\
\text { (around } 1000 \text { employees). } \\
\text { Farms mainly salmon and } \\
\text { sells locally and } \\
\text { internationally. }\end{array}$ \\
\hline $\begin{array}{l}\text { Fringe community } \\
\text { description }\end{array}$ & $\begin{array}{l}\text { Medium-sized rural community, } \\
\text { with a population of about } \\
25,000 \text { people. } \\
\text { The community is severely } \\
\text { affected by the liquid waste } \\
\text { disposal of the firm (pollution of } \\
\text { rivers/lakes). The community } \\
\text { accuses the company of } \\
\text { unsustainable deforestation. }\end{array}$ & $\begin{array}{l}\text { Very small rural community, } \\
\text { with a population of about } \\
5000 \text { people. } \\
\text { The community is gravely } \\
\text { affected by the firm's air } \\
\text { pollution (greenhouse gasses). } \\
\text { The company is accused of } \\
\text { allegedly depleting } \\
\text { underground water reserves. }\end{array}$ & $\begin{array}{c}\text { Small rural community, with a } \\
\text { population of about } \\
15,000 \text { people. } \\
\text { The community is affected } \\
\text { due to water and seabed } \\
\text { contamination from fish } \\
\text { farming activities. In the past } \\
\text { decade, the company has fired } \\
\text { community members, having } \\
\text { social consequences on the } \\
\text { settlement. }\end{array}$ \\
\hline Archival documents & 350 pages & 540 pages & 220 pages \\
\hline Number of interviews & 12 & 10 & 22 \\
\hline Fieldwork dates & April 2015 & October 2015 & March 2014 and January 2016 \\
\hline
\end{tabular}

\subsection{Data}

The qualitative data was gathered in multiple rounds during a four-year period (2014-2017), and from three different sources: archival documents, field observation, and intensive semi-structured interviews (Table 1).

Our first approach in the research sites was accessing several archival documents. The distinctive attribute of this source is we do not affect their construction [18], so it allowed us to determine and examine the chronology of events before, during, and after dialogues took place between each company and fringe community. Moreover, it permitted us to validate any emergent first-order concepts and second-order themes as the investigation progressed. Concerning the data accessed, we analyzed the companies' annual sustainability reports (2006-2017) to assess how each firm viewed and managed the relationship with their fringe community. Reports and memos produced by employees after dialogues took place were also reviewed, which helped us understand the dynamics and main events of the instances themselves. Press clippings (2012-2017) where the firms were mentioned also provided a complementary viewpoint of past happenings. Over 1100 pages of documents were analyzed.

Field observation was conducted by visiting each scenario at least once. One of the authors visited research site A in April 2015, and then research site B in October 2015 (on both occasions accompanied by a research assistant). Research site $C$ was visited twice: in 
March 2014 by one of the authors and a research assistant, and then in January 2016 by both authors. Therefore, four trips were made and each lasted two or three whole days. In these visits we witnessed three key situations: (1) we took part in various meetings where employees discussed the firm's relationship with their fringe community; (2) we observed two actual dialogues that occurred between a company-fringe community (in research site $C$ ) (this explains why we visited research site $C$ twice: to participate in an actual dialogue and observe and interview the participants); and (3) we were able to see employee and fringe community members' reactions following these two instances. Notes were taken during our visits (memo writing) to record any observations and insights. We followed Charmaz's [18] suggestion and kept a "methodological journal" to avoid any preconceptions. After transcription, we ended up with about 56 single-spaced pages of observation notes.

Additionally, during these visits intensive semi-structured interviews were conducted to validate and delve into emergent topics. This had the advantage of adding flexibility to clarify and further explore variables [19]. Protocols were designed prior to the actual interview process (Appendix A) using as a guide Charmaz's [18] book. Forty-four interviews were performed in total: 12 in site $A ; 10$ in site $B$, and 22 in site $C$ (Appendix B). On average, each lasted around $42 \mathrm{~min}$. We stopped by the forty-fourth interview, as we had reached theoretical saturation: each new comparison led to an already existing category, not adding anything new to the model. We ended up with about 390 single-spaced pages after transcription.

\subsection{Data Analysis}

Given our grounded theory approach $[18,19]$, we analyzed our qualitative data in three steps. First, after all qualitative data (i.e., archival, field observation, interviews) was obtained and transcribed by the authors and a research assistant, we performed a line-by-line review and an open or initial coding procedure. Each author performed this task independently with the help of the ATLAS.ti software, where we labeled all issues or ideas that emerged. Coding differences were settled by discussion between the authors while revisiting the data. After this process, we had over 370 different open or initial codes.

Next, the open or initial codes were grouped into higher-order concepts and themes to subsequently find tentative interrelations among them, in a process coined axial coding. This procedure narrowed down the codes to construct the categories that encompass fringe community dialogue. Figure 1 is a representation of this process, where we exemplify how we moved on from "first-order concepts" to "second-order themes", to then build three main conceptual dimensions: "Dialogue Groundwork", "Dialogue Conformation", and "Dialogue Reinforcement". For instance, notions like "money", "homes", and "donations" compose the "type of resources" theme. Here, we followed the constant comparison criterion of grounded theory, so as we progressed, we systematically contrasted the codes and categories obtained from the different sources of qualitative information. This permits the creation of analytic distinctions by finding the similarities and differences among the codes to derive the main categories and their sub-constructs. By drawing from different sources of information to understand the phenomenon, we were able to abstract the dimensions and underlying mechanisms in a holistic way [19]. In addition, using a similar procedure, we also found the existence of two enabling mechanisms that connect the three core dimensions of the process. These are simpler in nature, yet important constructs that emerged during the data analysis process but do not belong within the three aggregate dimensions of our model. Yet, we noticed that they are essential because they act as catalysts to smooth out the movement among the three categories. We called them "Dialoguing Attitude" and "Knowledge Accumulation". Figure 2 is a simplified representation of the coding procedure. 
First-order concepts

Second-order themes

Aggregate dimensions

\begin{tabular}{|l|}
\hline $\begin{array}{l}\text { Money, homes, donations, } \\
\text { jobs, clean environment... }\end{array}$ \\
\hline $\begin{array}{l}\text { Past conflicts, pending issues, } \\
\text { layoffs, resentment... }\end{array}$ \\
\hline $\begin{array}{l}\text { Expectations, greenwashing, } \\
\text { hidden agendas, antagonism... }\end{array}$ \\
\hline $\begin{array}{l}\text { Attendance costs, lack of } \\
\text { education, learning... }\end{array}$
\end{tabular}
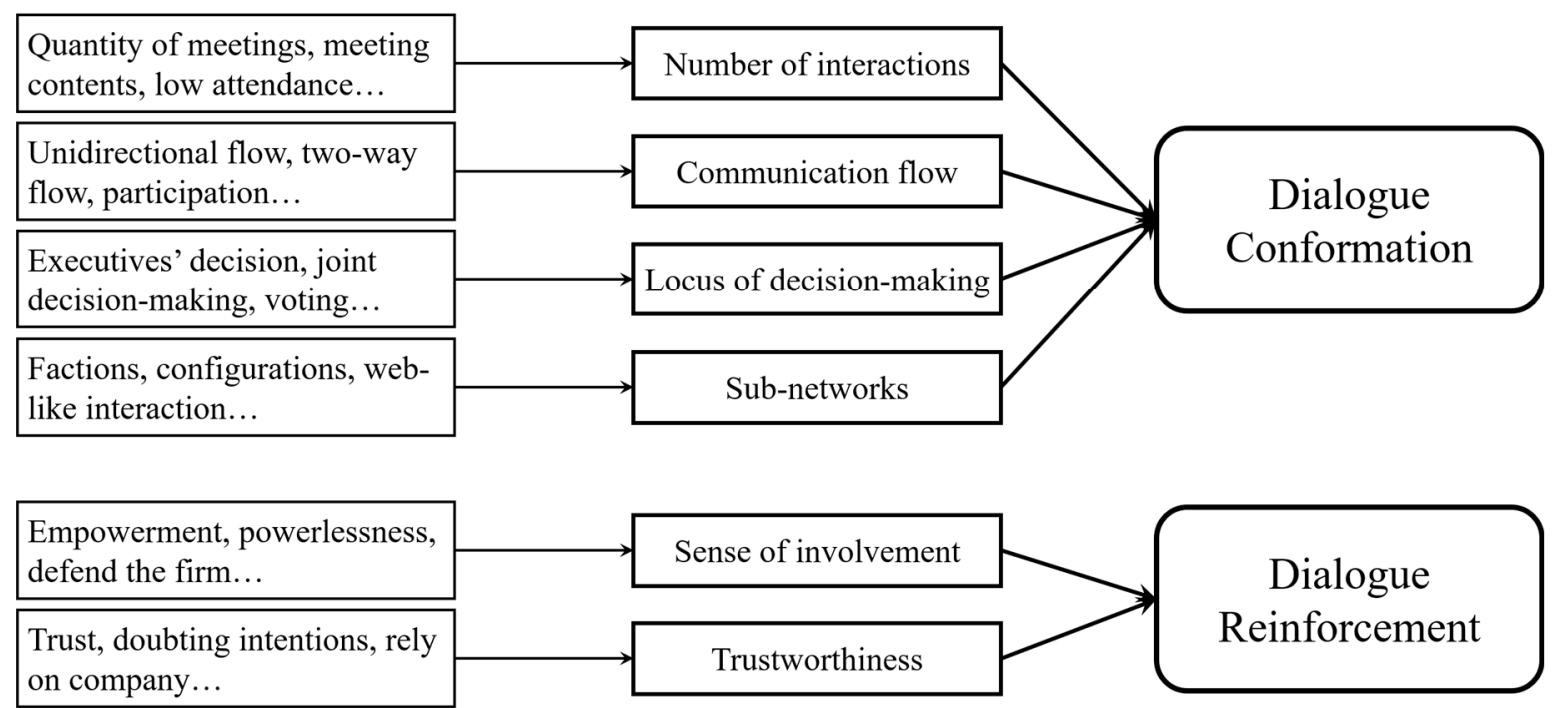

Figure 1. Representation of the coding procedure of the main dimensions.

First-order concepts Enabling mechanisms
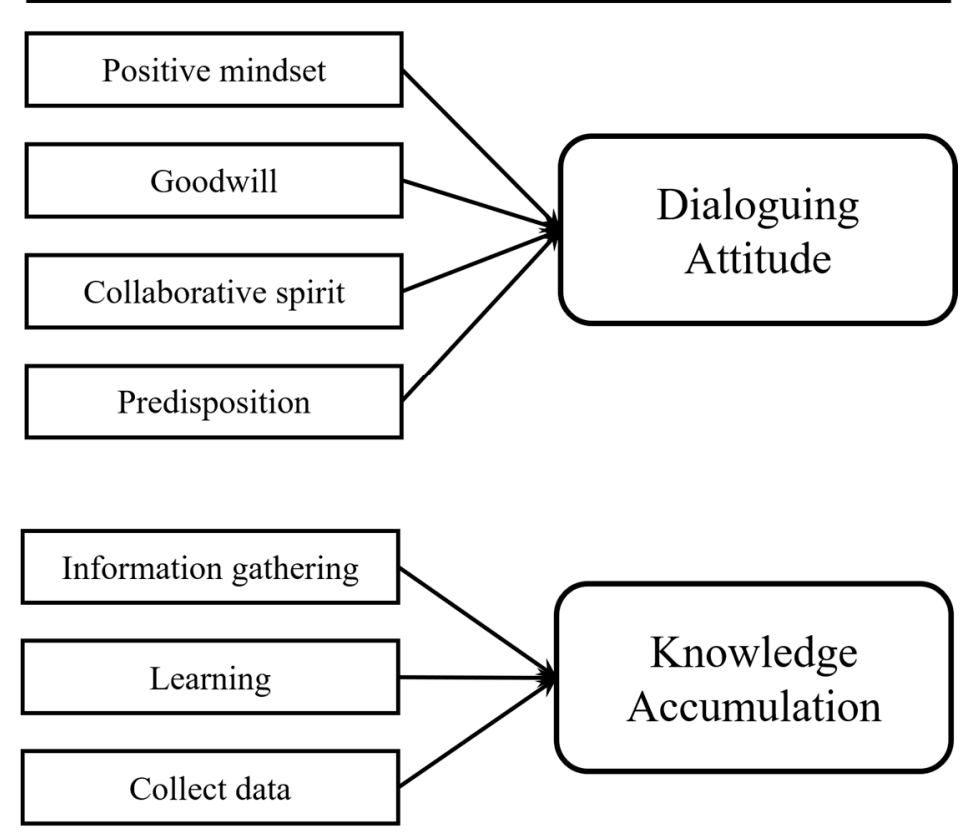

Figure 2. Representation of the coding procedure of the enabling mechanisms. 
Finally, we engaged in theoretical or selective coding to integrate the overarching dimensions into a conceptual model. This was done through an iterative procedure where we contrasted preliminary codes/concepts to emerging ones, so that a solid framework emerged by covering the various aspects of the process under inquiry. The objective was to discover how the three main dimensions and its sub-themes related to each other and build a coherent understanding of how the dialogue between companies and fringe communities occur. As shown in Figure 3, the three dimensions have a sequential nature: Dialogue Groundwork $\rightarrow$ Dialogue Conformation $\rightarrow$ Dialogue Reinforcement. The rationale is that there are some key issues that are necessary to start the dialogues, and the later phases build on the previous ones.

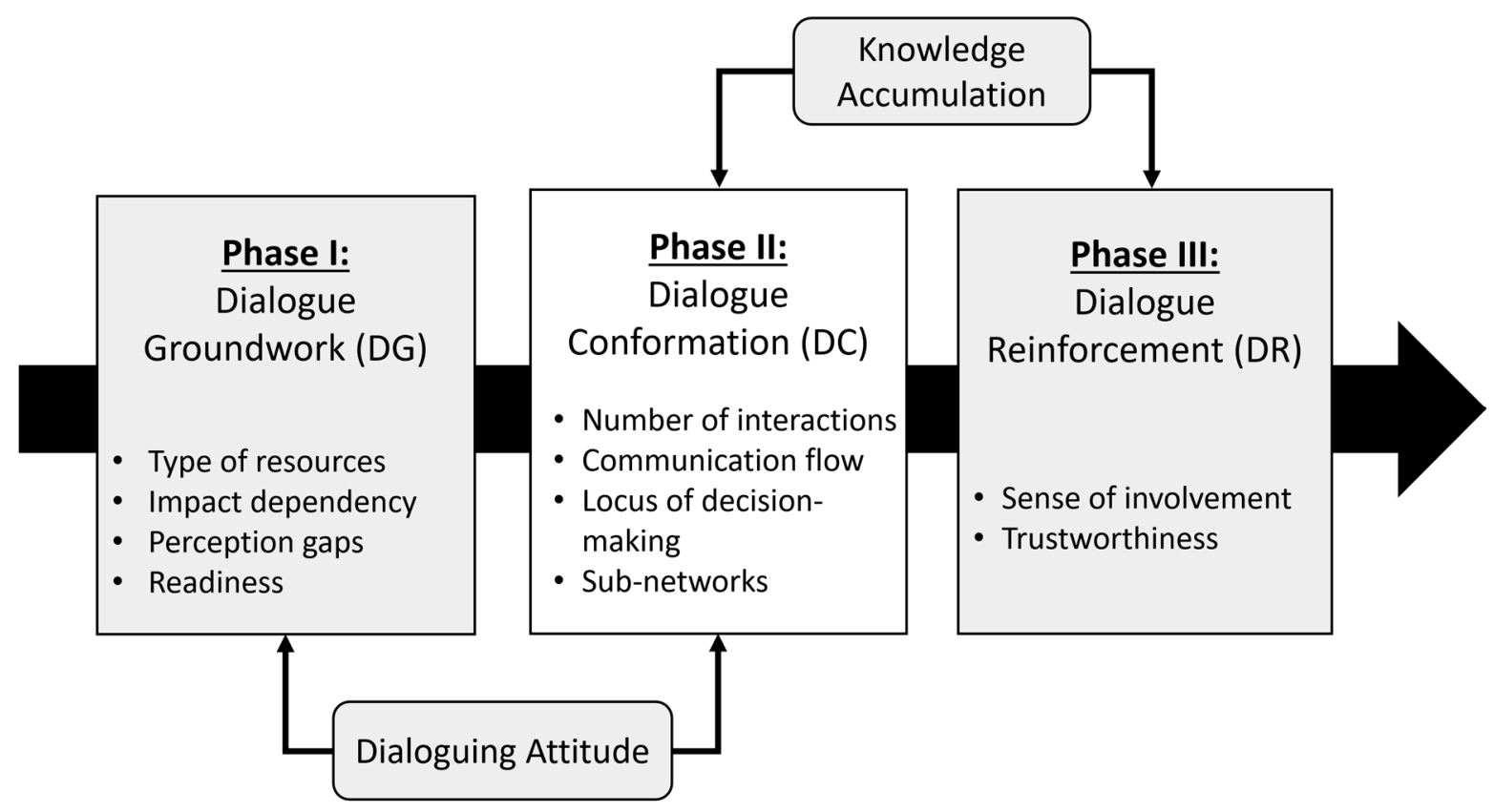

Figure 3. A model of fringe community dialogue.

\section{Results}

\subsection{General Overview of the Model}

From our analysis we inductively derived three dimensions that compose fringe community dialogue. We labeled them "Dialogue Groundwork", "Dialogue Conformation", and "Dialogue Reinforcement" (hereafter, DG, DC, and DR, respectively), and each describes a characteristic of the endeavor. Each dimension is subdivided into component themes that theoretically build it (Figure 1). These sub-variables were graded by contrasting the qualitative information to determine how the DG (4 subcomponents), DC (4 subcomponents), and DR (2 subcomponents) are shaped.

Our evidence and coding process suggest that the dimensions of our conceptual model have a sequential nature, so each dimension is a distinct step illustrating the structure and continuity of business-fringe community dialogue. The main rationale is that dialogues in this context happen to address specific socio-environmental grievances of the fringe community, and once these are solved the talks end. Phase I is composed of DG, phase II of DC, and phase III of DR. This order is explained because the DG sets the foundations of the business-fringe community dialogue (Phase I), as it encompasses planning aspects at the outset. This allows companies to prepare for talks with fringe stakeholders that have endured their condition for a long time. In way, it "levels the playing field" with fringe communities to begin conversations. The data showed that if these aspects are ignored at the beginning of the relationship, then the actual talks are hampered because unaddressed issues will necessarily divert or inhibit the talks. As we elaborate below, the forestry firm 
(site A) addressed most of the issues in this stage, which led to better occurring dialogues. The rationale is that because these groups have been systematically neglected, they need a previous step for everything to be in place before talks occur.

Once this has been configured, it is possible to move to Phase II where managers enter the dialogues themselves. This category involves operationalization aspects, so this step entails initiatives that build-up these talks. Due to fringe communities' attributes, they value certain aspects of dialogue over others. The information collected suggested that after the groundwork has been laid, then there are certain characteristics that will make the talks run smoother. Our evidence shows that without those matters, the dialogues end up in failure (e.g., participant attrition): this was the case of company in site C, where several participants ended up leaving because pre-dialogue and dialogue aspects of our model were not upheld.

Finally, once dialogues have begun, in Phase III the DR dimension contains features that accrue from conversations, which companies try to build to usher a long-lasting relationship. This is an end phase, once the dialogues are near termination (e.g., because a solution to the socio-environmental problems is reached), so that the fringe communities remain satisfied with the firm and the process. Therefore, despite that the dialogues might come to an end, our evidence showed that companies might still want to foster a long-term relationship in case the need for dialogues rises again. Therefore, to achieve this aim, there is the need to fulfill this category of our model. Evidence showed that this is the case, particularly in site A, where the forestry company consistently tried to get the fringe community members to trust the company to forge a long-lasting bond.

The existence of three phases is sustained because besides the three dimensions of business-fringe community dialogue, two enabling mechanisms emerged in our inquiry. We labelled them "Dialoguing Attitude" and "Knowledge Accumulation". These constructs are vital to the framework as they add dynamism to the three categories and allow movement throughout them by allowing their subcomponents to connect. These enabling mechanisms emerged because our data suggested these notions are necessary to facilitate the transitioning and make the dimensions interact. Dialoguing Attitude permits moving between Phases I to II and it represents participants' proclivity dialogue; and Knowledge Accumulation describes the interactions between Phases II and III, describing the learning that occurs because of the talks. Figure 3 is a visual representation of the derived model.

\subsection{Three Dimensions of Fringe Community Dialogue}

\subsubsection{Dialogue Groundwork}

This category encompasses considerations before fringe community dialogue happens. Therefore, companies not always rush into the enactment of the process until these matters are addressed. As these groups have unique attributes, the DG dimension acts as a predialogue stage that addresses any issues that could hinder the conversations, so it sets the foundation for a relationship between both parties. Our data showed this because, in contrast to company A, enterprises in locations B and C failed to build a basis for dialogues and prepare themselves and/or their fringe community before the instances took place.

Concretely, DG describes the assessments that enterprises make at the outset to improve the quality of the company-fringe community association. Our evidence reveals that this dimension can be subdivided into four subcomponents that unpack how to set the ground for a relationship, so conversations occur: "type of resources", "impact dependency", "perception gaps", and "readiness" (see Table 2 for the grading matrix). 
Table 2. Component concepts and grading matrix of the "Dialogue Groundwork" dimension.

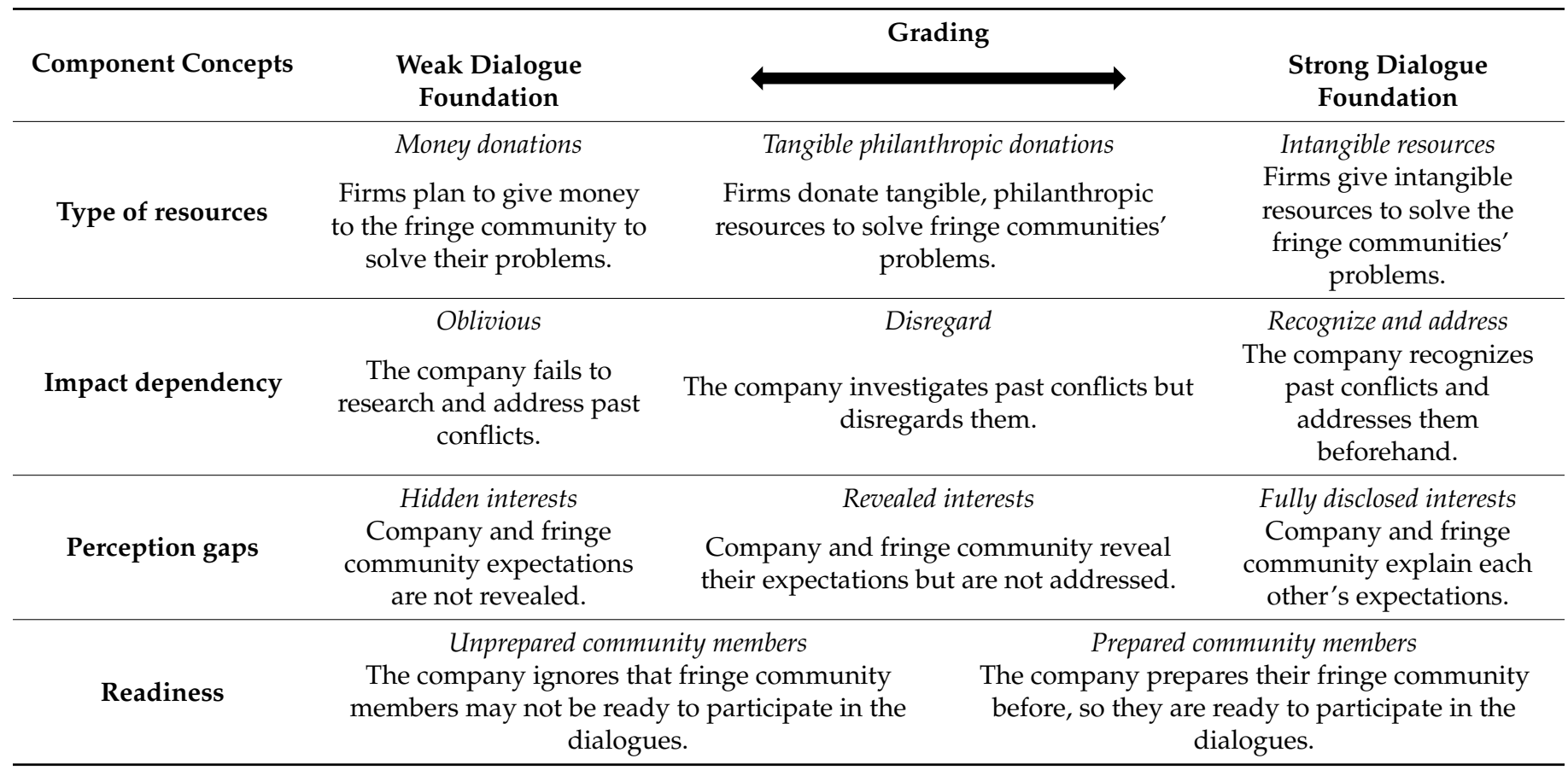

Regarding "type of resources", in this stage companies consider that dialogues require moving beyond money donations towards meaningful assets. Although archival data and memos showed fringe communities have basic needs entailing financial resources (e.g., staples), interviews revealed that this is not always so. Due to marginalization and the socio-environmental issues they face, other types of assets are needed too. Therefore, a first step is shifting to tangible philanthropic donations such as better homes/streets. Still, this may not solve the fringe community's problems, as years of isolation has left them excluded from society, and more purposeful assets will be required. Next is moving toward intangible resources, such as internship opportunities, university scholarships, or a cleaner ecosystem, which address deeper troubles of these groups (Table 2).

Thus, to set the foundations for dialogues, enterprises prepare to give the right resources their fringe community needs and realize that giving money is not enough. This emerged by comparing site A to locations B and C, as the mining and aquaculture companies had initially considered only monetary help. Nevertheless, they realized that certain demands could not be solved with this (e.g., scholarships and jobs). Contrarily, the forestry enterprise favored more meaningful tangible philanthropic assets for their fringe community, such as houses, and then moved toward intangible resources (i.e., employment opportunities). Therefore, as the planned resources shift from economic donations to philanthropic and then intangible resources, this engenders a better basis for dialogues because it allows providing the resources the stakeholder really needs. As a 44-year-old sustainability supervisor from site A expressed:

"The dialogues were aimed at achieving a positive long-term relationship with our neighbors. We were aware that people wanted something more than money. They wanted better homes, jobs, and opportunities in general, and we had a role to play in all this."

The second DG subcomponent is "impact dependency". Before dialogues ensue, companies research past conflicts that have involved the fringe community and firms. Our data suggests that community members may have pending issues that predate the entity's arrival. In all three locations archival data and interviews showed they resented firms' presence due to previous socio-environmental impacts, even if they were not the ones responsible for the damage: in location $\mathrm{A}$, problems with liquid waste were brought up; in 
$\mathrm{B}$, air pollution and depletion of underground water reserves were major issues; and in C, seabed contamination and layoffs were important. This implies that employees not always understand the fringe community's past experiences, so they must inquire beforehand to propose tailored solutions, even if they are not the ones accountable for these matters.

Companies should unearth previous problems through media and/or stakeholder analysis and gather information about issues that have historically affected the fringe community. The aquaculture company in site $C$ neglected this step and was oblivious regarding old conflicts. This affected the talks given that participants sidetracked the dialogues towards these matters. Contrarily, firms in the other two sites effected an examination of their fringe communities to comprehend prior issues. While the mining firm (location B) collected this information but disregarded it, the forestry enterprise (location A) recognized and addressed it later during the dialogues (Table 2). The contrast of these experiences indicates that firms cannot overlook the dependency on problems that fringe communities faced in the past, so to set the dialogue foundations these matters need to be investigated and engaged. Otherwise, diversions could happen, wasting time. As a 42-year-old farmer from site $\mathrm{C}$ mentioned:

"In the past, firms did as they pleased. This is the main cause of the contamination present in the area. This is why I find great that this company finally has something to say and can provide some sort of retribution to the damage done in the past."

The third subcategory of DG is "perception gaps": our evidence posits that firms manage beforehand the expectations that undermine talks. Interviews with fringe community members in sites $B$ and $C$ revealed they did not understand what companies expected out of the dialogues. Oftentimes these individuals assumed the existence of hidden agendas because they did not think of other reasons why companies would want to dialogue with a marginalized settlement. Archival reports revealed the enterprises' effort to convince community members of the benevolent motives driving the initiative. This diverted the objective of the dialogues (e.g., solve socio-environmental issues), hampering the process. On the other hand, all three firms expected an antagonistic attitude from community members, although dialogue memos indicated this was not always so: interviewees just wanted a better quality of life.

Hence, it is important to disclose both parties' expectations before meetings occur. The enterprise in site A initially fully disclosed the dialogues' aims, which facilitated the search for socio-environmental solutions during the instances that matched what the fringe community needed. Contrarily, firms in locations B and C had less effective approaches: while the former revealed the talks' significance but refused to address them before the dialogues, the latter's interests remained hidden overall (Table 2). As these tactics led to digression, airing out differences concerning the process is necessary. As a 49-year-old production executive from firm A mentioned:

"At first I felt that certain community members assisted to discover what we were really trying to achieve. If we were trying to impose our own interests and get some profit out of it. They did not understand that the aim of the dialogues was to reduce the impact that our company has on their lives."

"Readiness" is the last component concept of DG, and measures how prepared the fringe community is to be part of the dialogues. Three different types of readiness emerged in our investigation, which address community participants' inherent limitations so they can be part of the process: (i) participants' disruptive behaviors, (ii) costs of participation, and (iii) lack of pertinent information. Regarding (i), some fringe community members come with personal shortcomings. For example, archival reports show that some individuals were overly shy, while others vociferous. Therefore, the challenge was to manage loquacious community members, and get timid ones to speak up. To this end, firm A established a roundtable with mandatory, yet limited turns, which worked because louder factions restricted their responses, and quiet ones were incentivized to talk. 
Readiness (ii) calls companies to consider the costs of attending the dialogues. For some community members assisting meant missing out on important issues, like skipping work or less family time. If left unacknowledged, dialogue absenteeism could occur. In contrast to sites $\mathrm{A}$ and $\mathrm{B}$, in location $\mathrm{C}$ some participants stopped assisting because the aquaculture company ignored this. Readiness (iii) is linked to knowledge, which emerged because not all participants had the information to grasp the technicalities of companies' impact. Fringe community interviewees comprehended social issues that affected them directly (e.g., unemployment), but were less aware of science-based consequences of environmental damage. For example, in location B, community members did not understand the effects of greenhouse gases, and in site $C$ some people could not discern the repercussions of seabed pollution. This biased dialogues towards social issues, ignoring other impacts.

Altogether, unprepared community members could hinder the dialogue process because they are not ready to participate. If people do not talk, stop going, or do not understand the technicalities of the matters discussed, this could affect the instances. Thus, it is important for the dialogue foundations to acknowledge the possible disruptive behaviors of attendants, the costs of going, and their background knowledge to have a prepared community (Table 2) ready to take part in the conversation. As a 39-year-old sustainability executive of firm $C$ explained:

"We had a tough time explaining scientific aspects. Most community members wanted better homes or scholarships, but surprisingly few brought up environmental issues. People ignored the long-term effects of polluting the coastline, meaning we had to dedicate time to explain these matters."

Once the dialogue groundwork has been laid out in Phase I and dialoguing is possible, the process can move on to DC (Phase II; Figure 3).

\subsubsection{Dialogue Conformation}

This dimension centers on the implementation characteristics of the dialogues themselves. It describes operational aspects of the meetings to have well-organized talks considering the characteristics of fringe communities. Our evidence suggests that four subcomponents build the DC category: "number of interactions", "communication flow", "locus of decision-making", and "sub-networks" (see Table 3 for the grading matrix).

Table 3. Component concepts and grading matrix of the "Dialogue Conformation" dimension.

\begin{tabular}{|c|c|c|c|c|}
\hline \multirow[b]{2}{*}{ Component Concepts } & \multicolumn{4}{|c|}{ Grading } \\
\hline & $\begin{array}{l}\text { Poorly Organized } \\
\text { Dialogues }\end{array}$ & & & $\begin{array}{l}\text { Well-Organized } \\
\text { Dialogues }\end{array}$ \\
\hline \multirow[b]{2}{*}{$\begin{array}{l}\text { Number of } \\
\text { interactions }\end{array}$} & One or two & \multicolumn{2}{|c|}{ Few } & Iterative \\
\hline & $\begin{array}{l}\text { The company commits to } \\
\text { one or two encounters. }\end{array}$ & \multicolumn{2}{|c|}{ The company undertakes few meetings. } & $\begin{array}{l}\text { Several flexible instances } \\
\text { are planned and } \\
\text { implemented. }\end{array}$ \\
\hline Communication flow & \multicolumn{2}{|c|}{$\begin{array}{l}\text { The company just lets the fringe community know } \\
\text { and does not accept any feedback or opinions. }\end{array}$} & \multicolumn{2}{|c|}{$\begin{array}{c}\text { Two-way communication } \\
\text { Dialogues are a channel for bidirectional } \\
\text { communication, where firm and fringe community } \\
\text { exchange information. }\end{array}$} \\
\hline $\begin{array}{l}\text { Locus of decision } \\
\text { making }\end{array}$ & \multicolumn{2}{|c|}{$\begin{array}{l}\text { Firm executives } \\
\text { The dialogues do not have a joint decision-making } \\
\text { process, or this scheme is ignored, so firm } \\
\text { executives decide. }\end{array}$} & \multicolumn{2}{|c|}{$\begin{array}{l}\text { Joint decision making } \\
\text { A joint decision-making scheme is planned and } \\
\text { enacted, and executives respect the decisions } \\
\text { taken during the meetings. }\end{array}$} \\
\hline Sub-networks & $\begin{array}{l}\text { The firm sees the fringe } \\
\text { community as a } \\
\text { homogenous stakeholder. }\end{array}$ & $\begin{array}{l}\text { The company recogr } \\
\text { factions exist within } t\end{array}$ & $\begin{array}{l}\text { izes that one or two } \\
\text { e fringe community. }\end{array}$ & $\begin{array}{l}\text { Complex web-like network } \\
\text { The enterprise realizes that } \\
\text { several factions exist } \\
\text { within the fringe } \\
\text { community, forming a } \\
\text { web-like network. }\end{array}$ \\
\hline
\end{tabular}


The first sub-variable concerns the "number of interactions" between firms and fringe community. Evidence shows that as the quantity of dialogues grows, the chances of reaching agreements increases. This issue was patent in site $C$, given that in contrast to locations $\mathrm{A}$ and $\mathrm{B}$, aquaculture firm executives deemed that two instances sufficed. However, resistance to the agreed socio-environmental projects arose because not all fringe community representatives assisted and not all key topics were covered, forcing the company to undertake a third one. This led to a different set of solutions, and participants of the first two dialogues felt infringed.

Contrarily, because in sites A and B the companies favored more talks and were flexible on the number, this supports that several interactions are required. This increases the odds of having a representative sample of the fringe community and achieving a solution. Participants could be many, with different demands given their marginalized status, so several talks are needed to hone the initiatives to improve this stakeholder's condition. Otherwise, there is a risk of invalidating the procedure, as people could question the agreements. Contrasting field observations and interviews from all sites revealed that when few workshops are planned, members will not share the diagnosis or solutions agreed, doubting the validity of the process. However, when companies perform iterative meetings, then agreements are prone to represent the fringe community's demands, as it is considered a more democratic process (Table 3). If this is not considered, the bond deteriorates due to new or non-participants' discontent. As a 35-year-old salesman from site C commented:

"I went to all three workshops, and I felt that by the third one we were working well with the company. It is true that not all members were happy, but it was nice to work like this. It meant leaving past bad experiences behind. But I feel that more meetings were needed to make everybody happy."

The second DC subcomponent relates to changing how "communication flow" occurs between firm and fringe community. Field data and interviews revealed that in sites $\mathrm{B}$ and $C$ the companies had a stance of just "letting-the-community-know" their plans, and this unidirectional firm-to-community flow did not allow opinions from the latter. Fringe community members were dissatisfied because they could not convey their grievances, especially regarding the socio-environmental impacts on them.

Contrarily, as site A evidenced, dialogues imply shifting from a one-way monologue towards two-way communication (Table 3). This way, a joint evaluation of plans, concerns, and information was possible: participants were able to speak to somebody that cared about their problems. The forestry firm allowed the development of a bidirectional channel, where company and stakeholder could propose and assess activities. This allowed the enterprise to come closer to a well-organized dialogue because an effort was made to listen their demands, supporting the need for two-way conversations. As a 32-year-old saleswoman from location B emphasized:

"We have felt a change in this company's attitude towards us. At first dialogues were like a speech. They summoned us to a community center, late one day, and informed us what their plans were, and how they might impact us. Then they left and we could not say anything. But now we are able to express what we think and realize our suggestions are considered."

The most troublesome DC subcomponent for the company in site C was "locus of decision-making". Although the fringe community participated during the talks, it was aquaculture firm managers who decided the socio-environmental activities that were going to be implemented. In fact, firm executives omitted the project prioritization schemes made during the dialogues. This gave fringe community participants a false sense of joint decision making, which was sensed as hypocritical. In some cases, members even questioned the purpose of the whole process, to the point of publicly accusing the company of greenwashing.

Contrarily, firms in sites A and B permitted a joint decision-making process, where fringe community members were able to vote for their projects (Table 3). This hints that the 
locus of decision making cannot rest in the firm, but in the dialogues themselves. This is vital to achieve well-organized dialogues, as participants valued that somebody heard their opinions about what affects fringe communities. As a 47-year-old sustainability manager from the mining firm (site B) expressed:

"Community members received well that the social and environmental initiatives to implement had to be voted as part of the dialogue process. This showed them that we were not just trying to "clean our image", and that we were honestly trying to do something good for them."

The fourth DC subcomponent alludes to "sub-networks" or relationship configurations that appeared during the dialogues. When contrasting company memos with interviews we saw that fringe communities were composed of various factions: in site A, landowners resented farmers; in location B, people with indigenous background did not identify with others; and in site $C$, artisan fishermen had different demands than the rest of the community.

This entails that firms cannot treat this stakeholder as a homogenous group, and that the dialogue process is not dyadic or triadic in nature. Evidence shows that numerous subgroups existed, each with different needs, and sometimes interests could be conflicting. Each subgroup acted as a node that simultaneously interacted with the entity and other fringe community participants, so the links resembled a complex web-like network (Table 3). Sometimes subgroups joined to demand something, but in other occasions they fought over socio-environmental priorities. Hence, the relationship with this stakeholder resembles a web with multiple nodes, each with its own attributes and oftentimes conflicting demands, because not everybody within the fringe community experiences marginalization the same way. Therefore, balancing petitions, and reaching a consensus can be tough. As a 33-year-old production supervisor from firm A argued:

"Too many diverging interests were present in our first meetings. It was a disaster. Sometimes we had groups that fought for certain things, but at other times they joined to ask for other things. Multiple groups were constantly present during all dialogues [ ... ] and we had to devise ways to manage this issue and reach consensuses."

This section has described the DC subcomponents, whose consideration improves the organization of the meetings. According to our model, once Phases I and II have been addressed, then it is possible to move to the DR dimension (Phase III), which are aspects that develop near the end of the dialogues, once a consensus is reached, to allow the development of a long-lasting link.

\subsubsection{Dialogue Reinforcement}

This dimension groups two component concepts that companies aim to develop once the culmination of dialogues approaches, so that the fringe community ends satisfied with the process and a long-lasting relationship is built. Concretely, the variables that compose the DR dimension relate to intimate aspects that emerged when delving into the dialogue process, so participants feel it was successful and the company will be reliable in the future. The constructs are "sense of involvement" and "trustworthiness" (see Table 4 for the grading matrix). 
Table 4. Component concepts and grading matrix of the "Dialogue Reinforcement" dimension.

\begin{tabular}{|c|c|c|}
\hline \multirow[b]{2}{*}{ Component Concepts } & \multicolumn{2}{|c|}{ Grading } \\
\hline & Short-Term Relationship & $\begin{array}{l}\text { Long-Lasting } \\
\text { Relationship }\end{array}$ \\
\hline Sense of involvement & $\begin{array}{l}\text { False sense of empowerment } \\
\text { The fringe community perceives a false sense of } \\
\text { participation and power-holding because they do } \\
\text { not feel part of the dialogues. }\end{array}$ & $\begin{array}{l}\text { Real sense of empowerment } \\
\text { The fringe community feels they have a voice in } \\
\text { the dialogues, and sense they play a key role. }\end{array}$ \\
\hline Trustworthiness & $\begin{array}{l}\text { Low sense of trust } \\
\text { The fringe community senses that they cannot rely } \\
\text { on the company in the future. }\end{array}$ & $\begin{array}{l}\text { High sense of trust } \\
\text { The fringe community finds the dialogue process } \\
\text { altruistic in nature, and therefore feel that they can } \\
\text { rely on the company. }\end{array}$ \\
\hline
\end{tabular}

"Sense of involvement" appeared as a DR sub-variable because as dialogues advanced, it seemed relevant for the fringe community to "feel" part of the process. According to our data, this translates into a feeling of empowerment. Interviews from sites B and C mentioned they sometimes sensed a false sense of empowerment because the meetings led them to experience feelings of fake participation and power-holding. In the case of the aquaculture firm, this headed to failure because community members refused to keep participating. Consequently, participants tried seeking power in the media to attack the entity. Contrarily, in site A, various participants felt satisfied as they had a say in the socio-environmental projects decided. They felt a real sense of empowerment because they could choose-together with the company-their own fate (Table 4).

A high sense of involvement yields a long-lasting relationship between both parties because empowered fringe community members may stand-up for firms. For instance, after the dialogues in location A, participants recognized the forestry firm's intent to improve their quality of life by reducing the amount of liquid waste. Press clippings showed that participants defended the entity when non-community conflicts arose (e.g., when outsourced suppliers went on strike). Therefore, it seems important that following the dialogues companies cultivate a high sense of involvement in fringe community members, understood as the perception they were key in the meetings. This way the stakeholder feels empowered after years of isolation and neglect, which could translate into support towards entity and ultimately the construction of a long-lasting relationship. As a 32-year-old tourist guide from site B expressed:

"One of the reasons why I enjoyed going to the dialogues is because I felt that the people were truly connecting. The company was listening to our opinions, and I thought that we were being a significant part of the process."

"Trustworthiness" emerged as a DR subcomponent because many fringe community members developed feelings of trust/mistrust following the dialogues. Meetings can build/destroy firms' trustworthiness, understood as participants' perception if they can rely on the entity to solve socio-environmental issues. This was clear in location A: although tough at first, the forestry firm gained members' support as the dialogues progressed. Archival data suggested that after the meetings these individuals stopped doubting this entity's intentions. This happened because the aims of dialogues were perceived as altruistic, and the company followed-up and implemented the projects as decided during the talks. Therefore, a high sense of trust seems vital for the enterprise to continue its operations and avoid discontent.

Contrarily, in the other sites (B and C) a low sense of trust surged, meaning that the fringe community did not feel they could rely on the firm in the future (Table 4). Problems like neglecting past conflicts, failure to comprehend demands, and/or not addressing the readiness of the fringe community eroded this stakeholder's confidence in the company. This reflects that not fulfilling the steps of the previous phases directly affects the entities' trustworthiness. Fringe community interviewees from location $C$ revealed they stopped 
assisting the dialogues when they interpreted some of these steps as incomplete. They deemed the meetings not altruistic, and this loss of faith ended in failure for the aquaculture firm. In site B some members confessed that despite being satisfied, they were unsure if they could keep relying on the mining corporation, which hindered their long-term relationship following the dialogues.

The comparison of these accounts indicates that through open, democratic talks, companies can build their trustworthiness. This is relevant because fringe community's support depends on perceiving they can confide on the enterprise, insofar the meetings are an effective way to solve their demands. If achieved, firms are a step closer to building a long-lasting link with this stakeholder. As a 59-year-old artisan fisherman from location C said:

"I cannot trust their employees. They just want to do these dialogues so we stop protesting, and so that they can continue making money at our expense. I honestly thought that the dialogues would not achieve anything, so I refused to participate in any other initiatives."

\subsection{Enabling Mechanisms of Fringe Community Dialogue}

The two enabling mechanisms that emerged describe the dynamics of fringe community dialogue, as they explain how the dimensions are connected. They act as facilitators of the process, as they constitute constructs that elucidate how the sub-variables of our model affect each other. Table 5 presents a conceptual summary.

Table 5. Conceptual summary of the two enabling mechanisms of fringe community dialogue.

\begin{tabular}{|c|c|c|}
\hline Enabling Mechanism & Category Link & Enabling Dynamics \\
\hline \multirow{2}{*}{ Dialoguing attitude } & $\mathrm{DG} \rightarrow \mathrm{DC}$ & $\begin{array}{l}\text { Previous considerations of the DG improve the } \\
\text { collaborative mindset of participants, making the } \\
\text { elements of the actual meetings (DC) run better. }\end{array}$ \\
\hline & $\mathrm{DG} \leftarrow \mathrm{DC}$ & $\begin{array}{c}\text { Dialogue elements (DC) constitute an opportunity } \\
\text { to improve the relationship between both parties } \\
\text { when firms signal that overlooked pre-dialogue } \\
\text { considerations will be addressed (DG). }\end{array}$ \\
\hline \multirow{2}{*}{ Knowledge accumulation } & $\mathrm{DC} \rightarrow \mathrm{DR}$ & $\begin{array}{c}\text { Elements of the instances (DC) provide the } \\
\text { company knowledge about the fringe community, } \\
\text { which can be used to build a sense of involvement } \\
\text { and trust (DR). }\end{array}$ \\
\hline & $\mathrm{DC} \leftarrow \mathrm{DR}$ & $\begin{array}{l}\text { When fringe community members are empowered } \\
\text { and trust the process (DR), this eases the } \\
\text { accumulation of knowledge, which could then } \\
\text { improve the dialogues elements (DC). }\end{array}$ \\
\hline
\end{tabular}

\subsubsection{Dialoguing Attitude}

Following Figure 3, Phases I and II are linked through this mechanism, connecting the DG and DC categories. The former dimension sets the basis for dialogues, as it conveys the considerations that must be addressed beforehand. If fulfilled and a strong foundation is built (right-hand side; Table 2), evidence suggests this creates a positive mindset in both firm employees and fringe community members, which eases collaboration and makes talks more accessible. As this resembles a predisposition to dialogue, we labeled this connection "Dialoguing Attitude". This notion was particularly clear in location A, given that the forestry company was closer to fulfilling the DG phase: this firm opened to donating meaningful assets (e.g., jobs), addressed pending waste issues, closed the perception gaps associated to the dialogues, and prepared the fringe community participants. Given this, nearly all participants developed a positive predisposition towards the process because pre-dialogue considerations had been addressed, which smoothed the transition to the 
dialogues. The fringe community sensed a true attempt to lay the groundwork for the dialogues, generating an overall sensation of goodwill, and firm employees responded positively to this by also developing a good mindset that predisposed them to dialogue. As a 46-year-old production supervisor from site A mentioned:

"Once we began contacting some community members and told them about the whole process, we felt they were generally pleased with the idea of dialoguing with us, and especially with the fact that we were going to help them improve their lives. This of course motivated us to keep going and begin the talks as soon as possible."

Contrarily, when the DG subcomponents are closer to the "weak dialogue foundation" end (left-hand side; Table 2), this fragile foundation hinders cooperation and the parties' ability to work together. In this scenario, dialoguing is difficult because pre-dialogue considerations have not predisposed fringe community members to take part in this process. This was clear in location $C$ when compared to sites $A$ and $B$, where the aquaculture firm did not work previously with the fringe community and failed to tackle the points of the DG dimension. Concretely, the fishing entity only considered offering monetary resources, ignored past problems, left perception gaps unaddressed, and failed to prepare the fringe community members for the process. Hence, there was a rush to address the DC sub-variables without planning, so a predisposition to dialogue was not fostered by the participants. This emerged in the data because participants evoked a feeling of frustration once the dialogues begun, and both fringe community members and company employees felt uncomfortable and unwilling to begin dialoguing. They manifested a non-existent cooperative spirit because the foundations had not been laid out properly, which led then to less effective meetings. Hence, creating a good attitude towards dialoguing through the DG dimension is required when moving from Phase I to II.

The bidirectional nature of this enabling mechanism lies in that, during the dialogues, companies can notify the fringe community any decision made. Therefore, well-organized talks (DC; right-hand side; Table 3) could create a collaborative spirit among participants, which could facilitate the move back (from Phase II to I) to address any overlooked aspects of the DG category. This was the case in location B, where the mining company realized they hurried into dialoguing without planning (e.g., did not assess the resources needed and impact dependency). Therefore, employees leveraged the meetings to signal fringe communities members that previously overlooked DG aspects were going to be addressed (right-hand side; Table 2), which improved the overall predisposition to work together. Specifically, the mining firm informed that they would consider donating other assets that the fringe community needed (i.e., intangible ones), and also would try to somehow repair the damage done in the past (e.g., depleting aquifers). This had the effect of not only improving the Dialoguing Attitude, but also taking a step back in our model. As a 36-year-old bed-and-breakfast owner in site B said:

"Once the mining company opened up to considering other things we needed, such as repairing the environmental damage done in the past, just then did we as a community open up to really dialogue. Before that, we still kind of held a grudge against the company."

This enabling mechanism suggests that companies should be cautious when moving between the DG and DC dimensions. These categories connect by achieving a collaborative spirit. Otherwise, the motion between Phases I and II is hampered, and enterprises must diagnose which dimensions are unfulfilled, and work on them to improve the participants' Dialoguing Attitude.

\subsubsection{Knowledge Accumulation}

This enabling mechanism describes the interaction between Phases II and III (i.e., DC and DS; Figure 3). The characteristic of this construct is that well-implemented dialogues (DC; right-end in Table 3) provide an opportunity for companies to gather information and 
learn the nuances of the fringe community.

Archival reports and interviews showed that once dialogues begin, the process can improve thanks to iterative meetings and two-way communication. In each dialogue companies gather information on the fringe community, making each ensuing meeting better because joint decisions can be made, and sub-networks identified. These DCrelated aspects allow participants to feel involved (and empowered) by being part of the process and begin trusting the company (DR). The patent case was site A, where the forestry company had difficulties because they could not identify the factions within their fringe community. However, meeting after meeting, they were able to acknowledge the demands of this stakeholder, improving participants' feelings of empowerment and trust. Concretely, the data evinced that the forestry company was able to discover that there were at least two factions in the community: artisans and small-scale farmers, and each had a different set of demands. Yet, knowing this was only possible thanks to open bidirectional communication and repeated dialogues. Subsequently, by offering curated solutions to each subgroup, each faction independently began trusting the company and felt empowered thanks to the attention received. This shows that information collection in the DC dimension has the capability of enabling the DR. This implies that companies accumulate knowledge as the dialogues move on and learn about their fringe community. As a production manager in site $C$ stated:

"I think the only way we could have achieved the participants' trust is by listening to them during the dialogues. It is the only way to really know what they want."

The feedback part of this enabling mechanism lies in that if "sense of involvement" and "trustworthiness" (DR) have been accrued, they can they enhance knowledge accumulation in the future. When fringe community members feel empowered and trust the company, our research indicated that the implementation of the process becomes more effective, as the complex sub-network structure emerged clearer. Additionally, the bidirectional communication is more honest, which is another aspect of the DC dimension that improves. Consequently, Knowledge Accumulation is a key variable because a fulfilled DR category allows a better future conformation of meetings. For instance, in site A, the forestry company built during the process their fringe community's sense of involvement and trust. This eased the dialogues further on because the participants were more open and transparent about what they wanted to convey. From this, new subgroups emerged (e.g., businesspersons) and had the willingness to be more honest about what they wanted. Companies were therefore able to better address their specific needs, and this interplay made the talks smoother. As a 64-year-old farmer from site A said:

"Once we felt we could trust the forestry company it was easier for us to talk to the employees and tell them what we needed. Before it was impossible."

Therefore, the ability to accumulate knowledge from the dialogues is essential to move between the DC and DR categories. Being transparent and collecting key data from the fringe community allows companies to garner trust and make the stakeholder feel empowered., which feedbacks into better instances in the future. Without this effect, the movement is hindered, and the process is affected.

\section{Discussion}

Although extant theory has identified some general characteristics of stakeholder dialogue, e.g., $[3,12,13]$, we contribute to this tradition by revealing the need for more contextual approaches to this phenomenon. Inspired by Aakhus and Bzdak's [10] notion of "communication design practice", along with calls made, e.g., [1,6,33], we show that dialogue attributes vary depending on the type of stakeholder involved. Specifically, by studying talks between companies and fringe communities-an overlooked stakeholder in current literature $[23,58]$ - we evidence that this process has a unique structure and attributes that respond to contingent elements (i.e., stakeholder's features). While stakeholder dialogue literature advocates "generic" variables seemingly applicable to every 
context [11] such as openness [5], transparency [34], values [2], understanding [30], and monitoring [4], we challenge this notion. Instead, we argue and provide evidence that these prescriptions are not valid universally: though we realize these constructs may be relevant elsewhere, we prove that contextual elements make certain dialogue characteristics more important than others. Therefore, we concur with Mercer-Mapstone et al. [28] that dialogue is not something you just "do" devoid of setting.

The most important distinction between extant theory and our model concerns the structure of the dialogue. While Kaptein and van Tulder [26], Payne and Calton [37], and Golob and Podnar [27] recognize that dialogues need phases, these works fail to describe which these are. Pedersen [34] and Agudo-Valiente et al. [30] limit themselves to underscoring a "selection" stage, where firms choose participants to take part in the dialogues. Community-focused works, e.g., $[16,44,54]$ also suggest the importance of dialogue phases, but neglect to mention how these could be structured. Thus, considering there is no account of how fringe community dialogue is structured, one of our main contribution is unveiling the specific phases that are needed when dealing with this stakeholder, something that current literature fails to engage with. Our model indicates that when dialoguing with these marginalized groups there is a clear beginning (DG), middle (DC), and end stage (DR), because each specific phase adds something vital to facilitate the process of talking with this stakeholder. This is what we try to unpack in the following paragraphs.

Regarding Phase I (DG; Figure 3), stakeholder dialogue literature scantly mentions pre-dialogue matters beyond highlighting the need to build a common ground and address existing problems, e.g., $[8,32]$. However, we ignore how to achieve this with socially excluded groups due to, for example, poor education and resource access [52]. Our evidence indicates that to build a strong foundation for fringe community dialogue companies must allocate resources beyond money, address historic grievances and expectations, and make sure the stakeholder is ready to participate (Table 2). In a way, the DG dimension attempts to mend the fringe community's marginalization, and integrate them into society through essential goods, education, and fixing pending issues. Although this phase might resemble Mercer-Mapstone et al.'s [28] "pre-dialogue" stage, which seeks to avoid excluding participants from the talks, our model takes this idea further because the goal is to improve the fringe community's quality of life and level the "playing field" so fringe community members can be part of the conversation. This echoes with, for instance, recent bottom-of-the-pyramid (BOP) [59] and poverty alleviation [60] notions, where companies assume a social role to improve people's welfare. This seems to be the case with fringe communities because otherwise predating issues will divert the conversation.

Additionally, regarding the first phase (DG), literature from public relations and communication theory have increasingly studied the interplay between interlocutors during dialogues, but apparently knowledge from these traditions has not fully permeated to works on fringe community dialogue. To be precise, Gutiérrez-García et al. [13] in their review posit that "listening" and "openness to the other" (p. 745) are two necessary conditions for effective dialogues. The rationale is that only by paying attention and being honest regarding each parties' interests can these discourses reach a mutual understanding that is beneficial for actors involved $[1,30]$. However, the fact that this notion has not been formally incorporated in works focusing on fringe communities is particularly surprising, as one of the main obstacles that firms face when meeting with this stakeholder is the exiting power differential [23], and maybe by "listening" to this stakeholder in the early stages of the dialogue process, and by being "open" to consider its initial conditions, it could be a way to level the field and reduce the perceived power differential.

These ideas provide a stronger conceptual foundation for the DG category in our model, as this dimension's subcomponents entail certain aspects that the entity must study at the outset in order to attain an effective dialogue process. Otherwise, and as Skilton and Purdy [61] argue, when an uneven distribution of power exists, the less powerful party (the fringe community, in this case) could react negatively to companies' social and 
environmental responsible activities. Therefore, to fix this issue, the firm must address the type of resources that will be needed, the impact dependency of the relationship, the clearing up any perception gaps that exist, and the diagnosis of this stakeholders' readiness (see Table 2). Therefore, this points to the fact that hurrying unnecessarily to the actual talks, but without fulfilling the sub-variables of the DG to reduce the sensed power differential, could lead to failure. In sum, the ideas of "listening" and "openness" are essential to our model and to fringe communities, resonating with extant theory from related disciplines.

Concerning the implication of the dialogues (DC; Figure 3), two-way communication emerged as key variable, which matches this tradition's consensus, e.g., $[7,9,48]$. This confirms that dialogue necessarily implies bidirectional communication, regardless of the context. We thus uphold that this is a defining characteristic of dialogues versus other types of communication or public relation tactics. However, despite this overlap extant theory, other issues specific to fringe communities stand-out. An iterative number of interactions is especially important when meeting this stakeholder (Table 3), consistent with what Anguelovski [44] and Bowen et al. [43] claim. In line with Mena et al. [29], the rationale is that several instances are needed to get the fringe community onboard and allow them to express their concerns. As not everybody experiences isolation and poverty the same way, frequent meetings are necessary to reveal their views. Moreover, several dialogues are needed for this stakeholder to make sense of the issues discussed and form an opinion on the matter $[5,6]$. Only then will they have a democratic and effective voice at the table.

On how this stage (DC) relates to extant theory, most works that research aspects of fringe community dialogue usually focus only on this part of the process, and in fact the idea of two-way communication and a frequent number of interactions has already been mentioned in previous works [see, 44,48]. However, there are two new aspects that emerged in our framework that are completely new to extant theory: locus of decisionmaking and the attention to sub-networks (see Table 3). Concerning the former, literature usually assumes that firm executives decide on projects stemming from the dialogues, e.g., $[1,33]$. However, our model suggests that decision making should occur during the dialogues and make the fringe community part of the crafted solutions (Table 3). Otherwise, participants will feel infringed, lose faith in the process and lead to failure. In fact, without joint decision making the fringe community perceived a hostile environment, and this eventually led to absenteeism. Past works have indicated that when civil society members are involved (e.g., fringe community participants), this could shift managers' decisionmaking processes $[26,31,34,62]$. Nonetheless, our framework differs with this tradition in the sense that it is not necessary to change the whole structure of managerial decision making. Instead, and assenting with Whelan and Lyons [63], we suggest that it is enough to include community participants when prioritizing the socio-environmental initiatives to implement.

With reference to the sub-network sub-variable, this is another reason why several meetings are necessary: to reveal the factions within the fringe community. Although stakeholder dialogue literature recommends network analysis to identify the interrelations "among" groups, e.g., [6,10], a novel implication is that sub-network analysis is needed "within" this stakeholder (Table 3). Treating fringe communities like a homogenous group is a mistake because members have different backgrounds and experiences: for example, shop-owners and farmers have different priorities and demands, and these need to be researched and managed. Therefore, we contribute by advocating a change in level of analysis when performing network analysis: from between groups to within them. A strand of literature that could provide a deeper understanding of this DC category is network theory. Rowley [64] is one of the first articles to apply this rationale to stakeholder theory, and more recently Westermann-Behaylo et al. [65] also highlights the relevance of this mindset. Although these works apply this rationale across different stakeholders, in our model we find that it could be useful within fringe communities. Concretely, we mean that given that many "nodes" or subgroups exist within this specific stakeholder, then considering the existence of an intricate, web-like network with conflicting demands could 
help truly understand the micro-dynamics of the actual meetings. One of the essential articles in this tradition is the one by Roloff [66], where the author provides a three-step model to identify and manage multi-stakeholder networks. The phases are: "initiation", "deliberation", and "action", and each represent a different aspect of assessing and acting within the network. The benefit of this approach according to the author is that it allows to address and solve complex problems in cooperation with other groups. Nonetheless, our proposition is that this same rationale could be applied within fringe communities, so that firms could be able identify sub-factions inside this group, determine their interests, deliberate and finally act upon the decided projects. Consequently, using Roloff's [66] view as a starting point, we can expand what we know on this particular stakeholder, as its heterogeneity compels companies to follow the steps to become acquainted with subgroups, and understand the interrelations and dynamics among them.

DR, the final dimension of our model (Figure 3), is key for a long-lasting relationship with fringe communities once dialogues are near completion. Companies strive to involve this stakeholder not only in the process, but also into society (Table 4). This echoes Guibert and Roloff [4] and Mena et al.'s [29] assertions, that firms empower stakeholders by giving them what they need. We contribute by showing that this is true for fringe communities due to their features: by being poor, powerless, and marginalized, companies empower them by giving them the right resources (DG) and a voice (DC) to improve their well-being. This empowerment allows them to overcome exclusion. Concerning trustworthiness, firms trust builds naturally when they address the problems of these precarious communities (Table 4). Concurring with Kaptein and van Tulder [26] and Mercer-Mapstone et al. [9], we show that when somebody listens to them and helps them out of their misery, they are bound to start believing in the company.

Concerning how this adds to extant works, we highlight that this category emphasizes more psychological variables that emerge during the dialogues. Regarding "trustworthiness", Greenwood and Van Buren [67] emphasize that this is a key characteristic in company-stakeholder relationships, and from our model is stems that for fringe communities it is not the exception. Apparently, the reason is that under high levels of trust the association improves because the company is seen as a benevolent and valuable actor, and therefore there is a greater incentive for stakeholders to participate in any firm activity. On the other hand, Erdiaw-Kwasie et al. [68] mention the significance of fringe communities' sense of involvement, and its role is linked to the fact that empowerment yields stakeholder action. In this scenario, this perception leads to more effective dialogue, as community participants are more willing to keep being part of the talks.

The question remains, however, as it is not necessarily clear how firms can create higher levels of trust and sense of involvement. An interesting interpretation of this matter comes from Lacey et al. [22], who utilize justice theory to further explain this phenomenon. According to these authors, it is the notion of "procedural fairness" that could make fringe communities trust the entity and also feel involved in the dialogue process. This entails that members deem that the protocols and schemes through which decisions were made are deemed adequate and fair. Thus, it is vital that companies are transparent in relation to the rules and procedures that underlie the dialogue process, and that they respect these guidelines, so that fringe community members find the processes as just. In fact, this echoes with a recent study by George and Reed [69], which finds that strong feelings of procedural justice are enhanced when stakeholders feel they can trust the enterprise, and also that their participation was meaningful. All this is consistent with our model, which further supports the idea that justice theories could also extend and explain our findings.

Finally, an underlying issue of our work concerns the societal side of dialoguing with fringe communities. As established, these groups reside far from cities in underprivileged settlements. However, through the dialogue, companies can not only help local communities in overcoming their marginalization, but to really integrate them into society. Hence, our model indicates that when talking with these stakeholders there is a similarity to current BOP views, where companies focus on poverty alleviation and solving environmental 
issues [59]. This allows us to rethink businesses' role regarding people's basic rights [29], because it gives them the opportunity to fill in the government's role [70], as they have a response capacity way beyond any other societal actors [71]. Fringe community dialogue could be one of these scenarios where firms gain a social character, where they converse with stakeholders to provide things that governments fail to give, such as homes and education.

\section{Concluding Remarks}

By answering our research question, the main contribution of our work is acknowledging that fringe community dialogue has its unique nuances, which evinces why our model has a sequential and structured nature to understand how this process plays out. With our framework, we elucidate how companies engage in this process in a step-by-step method to better attend to these stakeholders' demands.

However, no publication is limitation free. As grounded theory research is based on certain research sites, it has no problems regarding internal validity as dimensions emerged directly from the qualitative data. However, because we are studying one country (Chile) and sector (extractive industries), this could affect its generalizability (external validity) to other settings. For this reason, future research should focus on studying this phenomenon in other industries that deal with fringe communities to expand or validate our model. Moreover, scholars should also develop quantitative studies (e.g., structural equation modeling) from our model, to see if the relationships we have found still hold. Additionally, as discussed here, the potential political role that firms may undertake in fringe settings suggest the need for more research in this contextual-dialogue process to understand to what extent firms may change their traditional role from a traditional business to social right providers.

The issues that fringe communities face are part of today's broader societal challenges. If we are to solve the problems that these marginalized stakeholders endure, it is essential to understand the complexity of the dialoguing with them. We hope that with our research we have cleared the path for scholars in this endeavor.

Author Contributions: Both authors contributed equally to the development of this article, specifically in its conceptualization, theoretical framing, methodology design, data analysis, and writingreviewing-editing. All authors have read and agreed to the published version of the manuscript.

Funding: This research received no external funding.

Institutional Review Board Statement: The study was conducted according to the guidelines of the Declaration of Helsinki.

Informed Consent Statement: Informed consent was obtained from all subjects involved in the study.

Data Availability Statement: The data are not publicly available due to confidentiality reasons.

Acknowledgments: We would like to thank former research assistant, Martin Wright, for his valuable help during the first phase of data collection, and for his collaboration in early drafts of this article.

Conflicts of Interest: The authors declare no conflict of interest.

\section{Appendix A. Semi-Structured Interview Protocol}

(Note: modifiable aspects of the interview are in italics, and especial questions for fringe community members are in [brackets].)

Introduction:

Hello, my name is researcher's name, and as you probably recall from our conversation over the phone, I am undertaking an academic investigation to know more about the community surrounding the company's operations. I want you to know that this research is not funded in any way by the company, so nobody in this firm has the authorization to know or see the information you are about to give me. Everything is absolutely confidential. We 
may quote you, but any academic use of this information will not be attributed to you, and you will not be identified by name. Therefore, please feel free to say whatever you want.

In compliance with research ethical standards and for the record, do you agree to voluntarily participate in this academic investigation? (Yes/No) You participated in the dialogue process with company's name in date and place, right?

Antecedents:

1. How was the first call to participate in the dialogue process? Who contacted you? What did they tell you?

2. [Have you ever been contacted by the company or any other firm before?] Why did you choose to participate? Did you really have a choice to participate or not?

3. What was your general opinion regarding this opportunity to participate?

4. [Why do you think the company chose you in particular? What impression did this cause you?] What were your expectations before engaging in dialogue with the community?

During the dialogue:

1. How and with who did you arrive to the dialogue process?

2. Who participated?

3. [Were the members of the company already there when you arrived? How was their reception? Did they receive you well?] What were your first impressions of the dialogue process?

4. Could you please describe the events that took place that day?

5. How would you describe the overall environment of the dialogue process?

6. What were the aspects that caught your attention?

7. Do you think your position or opinion was taken into consideration? Do you think the community member's positions or opinions were taken into account? Do you think the positions or opinions of other participants were taken into account?

\section{Outcomes:}

1. What were your impressions once the dialogue process ended?

2. What ideas or impressions were shared by the members that participated in this dialogue process?

3. What agreements did you reach?

4. Was the implementation of any projects actually agreed during these instances?

5. Has any decision or project been implemented since the dialogues ended?

6. Have you observed any change in the community?

7. Has the relationship between the company and the community changed? Presently, how is the relationship compared with that of other entities with this community?

Closure:

I want to thank you for your time and reemphasize that any information you have delivered is confidential and nobody in the company is authorized to see or know about it. Before ending this interview, is there anything else you would like to add or clarify regarding any topic we have discussed? Yes? No? Thank you very much. 


\section{Appendix B. Interviewee Information}

Table A1. Interview information by research site.

\begin{tabular}{ccc}
\hline Research Site & Firm Interviewees & Fringe Community Interviewees \\
\hline A & $\begin{array}{c}\text { Sustainability supervisor (1), production } \\
\text { executive (2), production supervisor (1), } \\
\text { production technician (2) }\end{array}$ & $\begin{array}{c}\text { Independent landowner (1), farmer (agriculture) } \\
\text { (2), homemaker (1), local businessman (1), } \\
\text { neighborhood council member (1) }\end{array}$ \\
\hline B & $\begin{array}{c}\text { Sustainability manager (1), production } \\
\text { supervisor (2), corporate affairs manager (1), } \\
\text { head of safety and occupational health (1) }\end{array}$ & $\begin{array}{c}\text { Local tourist guide (2), local businesswoman (1), } \\
\text { artisan (1), bed-and-breakfast owner (1) }\end{array}$ \\
\hline C & $\begin{array}{c}\text { Sustainability executives (2), production } \\
\text { manager (1), production supervisor (2), } \\
\text { production technician (1), corporate affairs } \\
\text { executive (2), head of human resources (1), } \\
\text { head of safety (1) }\end{array}$ & $\begin{array}{c}\text { Farmer (agriculture) (3), homemakers (2), } \\
\text { neighborhood council president (1), local } \\
\text { businessmen (2), principal of a public school (1), } \\
\text { chief of the fire department (1), artisanal } \\
\text { fisherman (1), city-hall employee (1) }\end{array}$ \\
\hline
\end{tabular}

\section{References}

1. Grygoruk, M.; Rannow, S. Mind the gap! Lessons from science-based stakeholder dialogue in climate-adapted management of wetlands. J. Envion. Manag. 2017, 186, 108-119. [CrossRef]

2. Stückelberger, C. Dialogue ethics: Ethical criteria and conditions for a successful dialogue between companies and societal actors. J. Bus. Ethics 2009, 84, 329-339. [CrossRef]

3. Ferri, L.; Pedrini, M.; Pilato, V. The management of stakeholder dialogue in different institutional contexts: An empirical study of FTSE4GOOD companies. J. Clean. Prod. 2016, 136, 226-236. [CrossRef]

4. Guibert, L.; Roloff, J. Stakeholder dialogue: Strategic tool or wasted words? J. Bus. Strateg. 2017, 38, 3-11. [CrossRef]

5. Chaudhri, V. Corporate social responsibility and the communication imperative: Perspectives from CSR managers. Int. J. Bus. Commun. 2016, 53, 419-442. [CrossRef]

6. Crane, A.; Glozer, S. Researching corporate social responsibility communication: Themes, opportunities and challenges. J. Manag. Stud. 2016, 53, 1223-1252. [CrossRef]

7. Burchell, J.; Cook, J. It's good to talk? Examining attitudes toward corporate social responsibility dialogue and engagement processes. Bus. Ethics Eur. Rev. 2006, 15, 154-170. [CrossRef]

8. Ferraro, F.; Beunza, D. Creating common ground: A communicative action model of dialogue in shareholder engagement. Organ. Sci. 2018, 29, 989-1236. [CrossRef]

9. Mercer-Mapstone, L.; Rifkin, W.; Louis, W.; Moffat, K. Meaningful dialogue outcomes contribute to laying a foundation for social license to operate. Resour. Policy 2017, 53, 347-355. [CrossRef]

10. Aakhus, M.; Bzdak, M. Stakeholder engagement as communication design practice. J. Public Aff. 2015, 15, 188-200. [CrossRef]

11. O'Riordan, L.; Fairbrass, J. Corporate social responsibility: Models and theories in stakeholder dialogue. J. Bus. Ethics 2008, 83, 745-758. [CrossRef]

12. Chen, Y.; Hung-Baesecke, C.; Chen, X. Moving forward the dialogic theory of public relations: Concepts, methods and applications of organization-public dialogue. Public Relat. Rev. 2020, 46, 101878. [CrossRef]

13. Gutiérrez-García, E.; Recalde, M.; Piñera-Camacho, A. Reinventing the Wheel? A comparative overview of the concept of dialogue. Public Relat. Rev. 2015, 41, 744-753. [CrossRef]

14. Hart, S.; Sharma, S. Engaging fringe stakeholders for competitive imagination. Acad. Manag. Exec. 2004, 18, 7-18.

15. McCarthy, L.; Muthuri, J. Engaging fringe stakeholders in business and society research: Applying visual participatory research methods. Bus. Soc. 2018, 57, 131-173. [CrossRef]

16. Holley, E.; Mitcham, C. The Pebble Mine dialogue: A case study in public engagement and the social license to operate. Resour. Policy 2016, 47, 18-27. [CrossRef]

17. Kalnins, A.; Dowell, G. Community characteristics and changes in toxic chemical releases: Does information disclosure affect environmental injustice? J. Bus. Ethics 2017, 145, 277-292. [CrossRef]

18. Charmaz, K. Constructing Grounded Theory, 2nd ed.; Sage Publications Ltd.: London, UK, 2014.

19. Corbin, J.; Strauss, A. Basics of Qualitative Research: Techniques and Procedures for Developing Grounded Theory, 4th ed.; Sage Publications Inc.: Thousand Oaks, CA, USA, 2015.

20. Shepherd, D.; Suddaby, R. Theory building: A review and integration. J. Manag. 2017, 43, 59-86. [CrossRef]

21. Babidge, S. "Socios": The contested morality of "partnerships" in indigenous community-mining company relations, Northern Chile. J. Lat. Am. Caribb. Anthr. 2013, 18, 274-293. [CrossRef]

22. Lacey, J.; Carr-Cornish, S.; Zhang, A.; Eglinton, K.; Moffat, K. The art and science of community relations: Procedural fairness at Newmont's Waihi Gold operations, New Zealand. Resour. Policy 2017, 52, 245-254. [CrossRef] 
23. Daudigeos, T.; Roulet, T.; Valiorgue, B. How scandals act as catalysts of fringe stakeholders' contentious actions against multinational corporations. Bus. Soc. 2020, 59, 387-418. [CrossRef]

24. Arenas, D.; Murphy, M.; Jáuregui, K. Community influence capacity on firms: Lessons from the Peruvian highlands. Organ. Stud. 2020, 41, 737-765. [CrossRef]

25. Andersen, S.; Høvring, C. CSR stakeholder dialogue in disguise: Hypocrisy in story performances. J. Bus. Res. 2020, 114, 421-435. [CrossRef]

26. Kaptein, M.; van Tulder, R. Toward effective stakeholder dialogue. Bus. Soc. Rev. 2003, 108, 203-224. [CrossRef]

27. Golob, U.; Podnar, K. Critical points of CSR-related stakeholder dialogue in practice. Bus. Ethics Eur. Rev. 2014, 23, 248-257. [CrossRef]

28. Mercer-Mapstone, L.; Rifkin, W.; Moffat, K.; Louis, W. Conceptualizing the role of dialogue in social license to operate. Resour. Policy 2017, 54, 137-146. [CrossRef]

29. Mena, S.; de Leede, M.; Baumann, D.; Black, N.; Lindeman, S.; McShane, L. Advancing the business and human rights agenda: Dialogue, empowerment, and constructive engagement. J. Bus. Ethics 2010, 93, 161-188. [CrossRef]

30. Agudo-Valiente, J.; Garcés-Ayerbe, C.; Salvador-Figueras, M. Corporate social performance and stakeholder dialogue management. Corp. Soc. Responsib. Environ. Manag. 2015, 22, 13-31. [CrossRef]

31. Burchell, J.; Cook, J. Sleeping with the enemy? Strategic transformations in business-NGO relationships through stakeholder dialogue. J. Bus. Ethics 2013, 113, 505-518. [CrossRef]

32. Lane, A. If it's so good, why not make them do it? Why true dialogue cannot be mandated. Public Relat. Rev. 2018, 44, 656-666. [CrossRef]

33. Passetti, E.; Bianchi, L.; Battaglia, M.; Frey, M. When democratic principles are not enough: Tensions and temporalities of dialogic stakeholder engagement. J. Bus. Ethics 2019, 155, 173-190. [CrossRef]

34. Pedersen, E. Making corporate social responsibility operable: How companies translate stakeholder dialogue into practice. Bus. Soc. Rev. 2006, 111, 137-163. [CrossRef]

35. Miles, M.; Munilla, L.; Darroch, J. The role of strategic conversations with stakeholders in the formation of corporate social responsibility strategy. J. Bus. Ethics 2006, 69, 195-205. [CrossRef]

36. De Graaf, F. CSR as value attunement within governance processes: Stakeholder dialogue, corporate principles and regulation. Bus. Soc. Rev. 2016, 121, 365-390. [CrossRef]

37. Payne, S.; Calton, J. Exploring research potentials and applications for multi-stakeholder learning dialogues. J. Bus. Ethics 2004, 55, 71-78. [CrossRef]

38. Murphy, M.; Arenas, D. Through indigenous lenses: Cross-sector collaborations with fringe stakeholders. J. Bus. Ethics 2010, 94, 103-121. [CrossRef]

39. Roper, J.; Collins, E.; de Jong, J. Lake Taupo: A multi-sector collaborative partnership towards sustainable development. J. Public Aff. 2015, 15, 143-152. [CrossRef]

40. Dey, T.; Pala, N.; Shukla, G.; Pal, P.; Das, G.; Chakarvarty, S. Climate change perceptions and response strategies of forest fringe communities in Indian Eastern Himalaya. Environ. Dev. Sustain. 2018, 20, 925-938. [CrossRef]

41. Dunham, L.; Freeman, R.; Liedtka, J. Enhancing stakeholder practice: A particularized exploration of community. Bus. Ethics Q. 2006, 16, 23-42. [CrossRef]

42. Calvano, L. Multinational corporations and local communities: A critical analysis of conflict. J. Bus. Ethics 2008, 82, 793-805. [CrossRef]

43. Bowen, F.; Newenham-Kahindi, A.; Herremans, I. When suits meet roots: The antecedents and consequences of community engagement strategy. J. Bus. Ethics 2010, 95, 297-318. [CrossRef]

44. Anguelovski, I. Understanding the dynamics of community engagement of corporations in communities: The iterative relationship between dialogue processes and local protest at the Tintaya copper mine in Peru. Soc. Nat. Resour. 2011, 24, 384-399. [CrossRef]

45. Dare, M.; Schirmer, J.; Vanclay, F. Does forest certification enhance community engagement in Australian plantation management? For. Policy Econ. 2011, 13, 328-337. [CrossRef]

46. Dorobantu, S.; Odziemkowska, K. Valuing stakeholder governance: Property rights, community mobilization, and firm value. Strateg. Manag. J. 2017, 38, 2685-2703. [CrossRef]

47. McDonald, P.; Mayes, R.; Pini, B. Mining work, family and community: A spatially-oriented approach to the impact of the Ravensthorpe nickel mine in remote Australia. J. Ind. Relat. 2012, 54, 22-40. [CrossRef]

48. Ni, L.; Wang, Q.; de la Flor, M.; Peñaflor, R. Ethical community stakeholder engagement in the global environment: Strategies and assessment. Public Relat. J. 2015, 9, 1-22.

49. Parsons, R. We are all stakeholders now: The influence of western discourses of "community engagement" in an Australian aboriginal community. Crit. Perspect. Int. Bus. 2008, 4, 99-126. [CrossRef]

50. Tarras-Wahlberg, N. Social license to mine in Sweden: Do companies go the extra mile to gain community acceptance? Min. Econ. 2014, 27, 143-147. [CrossRef]

51. McCarthy, L. Empowering women through corporate social responsibility: A feminist Foucauldian critique. Bus. Ethics Q. 2017, 27, 603-631. [CrossRef]

52. Yakovleva, N.; Vazquez-Brust, D. Multinational mining enterprises and artisanal small-scale miners: From confrontation to cooperation. J. World Bus. 2018, 53, 52-62. [CrossRef] 
53. Keenan, J.; Kemp, D.; Ramsay, R. Company-community agreements, gender and development. J. Bus. Ethics 2016, 135, 607-615. [CrossRef]

54. Lehtimaki, H.; Kujala, J. Framing dynamically changing firm-stakeholder relationships in an international dispute over a foreign investment: A discursive analysis approach. Bus. Soc. 2017, 56, 487-523. [CrossRef]

55. Rodrigo, P.; Duran, I.J.; Arenas, D. Does it really pay to be good, everywhere? A first step to understand the corporate social and financial performance link in Latin American controversial industries. Bus. Ethics Eur. Rev. 2016, 25, 286-309. [CrossRef]

56. Beckman, T.; Colwell, A.; Cunningham, P. The emergence of corporate social responsibility in Chile: The importance of authenticity and social networks. J. Bus. Ethics 2009, 86, 191-206. [CrossRef]

57. Devenin, V.; Bianchi, C. Soccer fields? What for? Effectiveness of corporate social responsibility initiatives in the mining industry. Corp. Soc. Responsib. Environ. Manag. 2018, 25, 866-879. [CrossRef]

58. Davila, A.; Molina, C. From silent to salient stakeholders: A study of a coffee cooperative and the dynamic of social relationships. Bus. Soc. 2017, 56, 1195-1224. [CrossRef]

59. Beckett, J.; Chmielewski, D.; Dembek, K. Taking the time to understand time at the bottom/base of the pyramid. Bus. Soc. 2020. [CrossRef]

60. Medina-Muñoz, R.; Medina-Muñoz, D. Corporate social responsibility for poverty alleviation: An integrated research framework. Bus. Ethics Eur. Rev. 2020, 29, 3-19. [CrossRef]

61. Skilton, P.F.; Purdy, J.M. Authenticity, power, and pluralism: A framework for understanding stakeholder evaluations of corporate social responsibility activities. Bus. Ethics Q. 2016, 27, 99-123. [CrossRef]

62. Arenas, D.; Sanchez, P.; Murphy, M. Different paths to collaboration between businesses and civil society and the role of third parties. J. Bus. Ethics 2013, 115, 723-739. [CrossRef]

63. Whelan, J.; Lyons, K. Community engagement or community action: Choosing not to play the game. Environ. Polit. 2005, 14, 596-610. [CrossRef]

64. Rowley, T.J. Moving beyond dyadic ties: A network theory of stakeholder influences. Acad. Manag. Rev. 1997, 22, 887-910. [CrossRef]

65. Westermann-Behaylo, M.K.; Van Buren III, H.J.; Berman, S.L. Stakeholder capability enhancement as path to promote human dignity and cooperative advantage. Bus. Ethics Q. 2016, 26, 529-555. [CrossRef]

66. Roloff, J. Learning from multi-stakeholder networks: Issue-focused stakeholder management. J. Bus. Ethics 2008, 82, 233-250. [CrossRef]

67. Greenwood, M.; Van Buren III, H.J. Trust and stakeholder theory: Trustworthiness in the organization-stakeholder relationship. J. Bus. Ethics 2010, 95, 425-438. [CrossRef]

68. Erdiaw-Kwasie, M.O.; Alam, K.; Shahiduzzaman, M. Towards understanding stakeholder salience transition and relational approach to "better" corporate social responsibility: A case for a proposed model in practice. J. Bus. Ethics 2017, 144, 85-101. [CrossRef]

69. George, C.; Reed, M.G. Revealing inadvertent elitism in stakeholder models of environmental governance: Assessing procedural justice in sustainability organizations. J. Environ. Plan. Manag. 2017, 60, 158-177. [CrossRef]

70. Scherer, A.; Palazzo, G. The new political role of business in a globalized world: A review of a new perspective on CSR and its implication for the firm, governance and democracy. J. Manag. Stud. 2011, 48, 899-931. [CrossRef]

71. Matten, D.; Crane, A. Corporate citizenship: Towards an extended theoretical conceptualization. Acad. Manag. Rev. 2005, 30, 166-179. [CrossRef] 